\title{
Green gold
}

\section{The round-up on last year's global investment in clean energy shows that renewables continued their rapid ascendancy, bringing multiple benefits for all.}

\begin{abstract}
Bloomberg New Energy Finance recently released their clean energy investment figures for 2015 (http://go.nature.com/grRyGc). The numbers make for fascinating reading. Not only did last year see a new record for installed wind and photovoltaic capacity (64 GW and $57 \mathrm{GW}$, respectively), but it also set a new bar for global investment at US $\$ 329$ billion. Breaking the numbers down, however, reveals some unexpected trends and developments.

The bulk of the global investment (some US $\$ 199$ billion) came in the form of financing for utility-scale energy projects. Solar and wind farms, biomass plants, and small hydroelectric schemes are clearly on the rise, buoyed by falling costs and expanding policy support for renewable schemes.
\end{abstract}

\section{For any nation looking to boost employment, clean energy is increasingly a promising choice.}

On a national scale, China once again comes out on top with an investment of US $\$ 110.5$ billion, spurred by its continuing desire to meet growing energy demand while cutting pollution and cleaning its cities' air. Their total represents nearly double that of second place USA. Disappointingly, given its historic stance on climate change and early adoption of renewables, Europe continues to show a net decline from its 2011 peak, despite the continued championing of renewable energy from many of its constituent nations. Germany and France saw significant drops in investment, although the UK witnessed a growth of some $24 \%$, which is somewhat surprising given the policy turnarounds and subsequent uncertainty witnessed throughout 2015.

But perhaps most striking was the finding that non-OECD (Organisation for Economic Co-operation and Development) countries represented $50 \%$ of the market, while new markets like Mexico, Chile, South Africa and Morocco saw enormous gains in investment, over double or even triple their past amounts in some cases. These developments surely cement the expansion of clean energy as a truly global trend.

These new records and the growing national variations are staggering, especially in light of the low oil prices over the past eighteen months. Considering that the installed capacity for renewables recently surpassed that of fossils (http://go.nature.com/Xt5j7q), it's hard not to feel that a turning point has been reached, as argued elsewhere in this issue in a Perspective by Catherine Mitchell (article number 15030). Not only have the costs of technologies like solar photovoltaics reduced and become increasingly cost competitive, but support for renewable energy continues to rise. The report puts the global accord at the outcome of the 2015 Paris Climate Conference (COP21) as perhaps the natural culmination of that year's growth. Although many have criticized the true impact and heft that the agreement may have, it's hard not to look back across the whole of 2015 in the light of these figures and see a real change in momentum one that we can only hope is going to be sustained throughout the coming years.

The investment growth is also good news for science and technology. The surge in new capacity and financial support should serve to strengthen demands for continued funding for research and development, from both the private and public sector. Supporting and expanding scientific endeavours can only help further in terms of cost reduction for existing technologies but also with the innovation of new concepts and approaches. Systems like the Ouarzazate Solar Power Station under construction in Morocco, are a case in point. This plant relies on concentrated solar power to store energy as heat in molten salts. New thermal storage materials and new structures to help track the Sun can both bring down costs and increase efficiency for future plants.

The growth in financial investment also brings with it a growth in jobs. Solar panels don't just appear on buildings when you're not looking (although at the rate of rooftop expansion in Japan and Australia you'd be forgiven for thinking otherwise). Indeed, The Solar Foundation in the US recently found that the number of jobs in the domestic solar industry has doubled over the past five years, with some 35,000 being added in 2015 (http://go.nature.com/IU4WPp). The same number are currently projected to appear in 2016. This means there are now more people in the US employed in solar than there are in oil and gas extraction. For any nation looking to boost employment, particularly in the light of continued redundancies in the fossil industry, clean energy is increasingly a promising choice, climate commitments notwithstanding.

That's exactly what the International Renewable Energy Agency (IRENA) suggested for the Gulf Cooperation Council region - which consists of Bahrain, Kuwait, Oman, Qatar, Saudi Arabia and the United Arab Emirates - in a recent report (http://go.nature.com/Ys1tiw). Their energy market analysis of the area finds that an expansion of clean energy technologies - notably concentrated solar power, rooftop and utility-scale solar photovoltaics, wind, and wasteto-energy - could generate more than 200,000 jobs by 2030 . This is of course in addition to potentially significant reductions in greenhouse gas emissions, fuel consumption and water usage.

IRENA believes its recommendations are achievable. Nonetheless, implementing them and then meeting the targets requires new policy instruments, legal frameworks, and changes in regulation, all of which demand political will. Given the current fossil fuels strategy of OPEC, there are perhaps reasons to doubt this might happen. However, the aspiration is there: for example, the energy minister of the United Arab Emirates, Suhail Al Mazrouei, has said that up to $30 \%$ of their needs could come from clean energy (http://go.nature.com/F8q6Kz).

This kind of leadership - here as elsewhere in the globe - is important, but it must be translated into action. Given the figures discussed above, it's hard not to believe that the barrier to that action is getting lower all the time. With continued financial and policy support, the benefits of clean energy are there for all to reap. 